\title{
The Impact of COVID-19 on Mental Health
}

\author{
Donart Koci*, Festina Morina*, Fatlinda Hoxhaj*, Antigona Ukëhaxhaj* \\ University of Gjakova "Fehmi Agani”, Gjakova, 50000, Kosovo \\ Received: November 19, 2020. Revised: May 4, 2021. Accepted: June 2, 2021. Published: June 3, 2021.
}

\begin{abstract}
Infection with the new coronavirus (severe acute respiratory syndrome coronavirus 2 , or SARS-CoV2) causes coronavirus disease 2019 (COVID-19). The virus that causes COVID-19 spreads easily among humans and more continues to be detected over time as to how it spreads. The effect that this crisis will have on the mental health of the population, both in the short and long term, is unknown. In the acute phase, fears of possible exposure to infection, loss of employment, and financial strain are likely to increase psychological distress in the wider population. In the long run, grief and trauma are likely to appear as financial and social impacts become ingrained, the risk of depression and suicide may increase. Lack of hugs, handshakes, free movement and isolation have made it impossible for people to socialize and behave normally with each other. Anxiety, fear, insecurity and lack of selfconfidence are some of the main problems that people faced during quarantine and that they may face after the release of the measures. The purpose of this paper is to prove how much the Pandemic and the situation with COVID-19 have affected the mental health of the population in the city of Prizren and Gjakova. Quantitative study method was used for the realization of this work. This paper is based on the data extracted from the questionnaire completed together with the citizens of the municipalities of Prizren and Gjakova. For the realization of this scientific research are involved 200 citizens. Age groups, gender, economic status, level of education and place of residence were analyzed. The study included people aged 20 to 50 years. The most included gender in the study is the female with $59 \%$ while the male gender with $41 \%$. All results are presented in graphs worked with SPSS program.
\end{abstract}

Keywords: COVID-19, mental health, stress, anxiety

\section{INTRODUCTION}

"A life saved can be your life or the life of your family, so now more than ever we need to stand together to defeat this virus that is taking lives" [1]

Coronaviruses are a group of viruses belonging to the family Coronaviridae, which infect both animals and humans. Human coronaviruses can cause mild illness, similar to a common cold, while others cause more serious illness (such as MERS -
Middle East Respiratory Syndrome and SARS - Rare Acute Respiratory Syndrome). A new coronavirus not previously identified in humans appeared in Wuhan, China in December 2019. [2]

Infection with the new coronavirus (severe acute respiratory syndrome coronavirus 2, or SARS-CoV-2) causes coronavirus disease 2019 (COVID-19). The virus that causes COVID-19 spreads easily among humans and more continues to be detected over time as to how it spreads. The data have shown that they spread mainly from person to person among those who are in close contact (within about 6 meters, or 2 meters). The virus is spread by the airways released when someone with the virus coughs, sneezes, breathes, sings or talks. These drops can be inhaled or dropped into the mouth, nose or eyes of a person nearby. [3]

Like previous coronaviruses, the new coronavirus causes respiratory illness and symptoms affect respiratory health. According to the Centers for Disease Control and Prevention (CDC), the main symptoms of COVID-19 can be very mild to severe and include fever, cough, and shortness of breath. Many people are asymptomatic. Symptoms may appear two to 14 days after exposure. Current information suggests that the virus can cause mild flu-like symptoms as well as more serious illness.[4]

\section{COVID-19}

Coronaviruses are a type of virus. There are many different types, and some cause disease. A newly identified coronavirus, SARS-CoV-2, has caused a worldwide pandemic called COVID-19. By now, researchers know that the new coronavirus spreads through droplets released into the air when an infected person coughs or sneezes. The points generally do not travel more than a few meters and they fall to the ground (or above the surface) for a few seconds - this is why physical distancing is effective in preventing spread. [5] It is estimated that between late November and early December 2019 in the People's Republic of China, in Wuhan City in Hubei Province, an epidemiological event of interest occurred when a series of reports of pneumonia of unknown origin surfaced among the population; Wuhan virus was initially named, later renamed $2019-\mathrm{nCoV}$ (new coronavirus 2019) and determined to be an agent of the coronavirus family, closely related to SARS-CoV, the causative agent of severe acute respiratory syndrome 2003 (SARS ). [6]

The SARS-CoV-2 genome has been reported over $80 \%$ identical to previous human coronavirus (naked natural as 
SARS). Structural proteins are encoded by four structural genes, including spike $(\mathrm{S})$, envelope $(\mathrm{E})$, membrane $(\mathrm{M})$, and nucleus-occipid $(\mathrm{N})$ genes. Orflab is the largest gene in SARS-CoV-2 which encodes the pplab protein and 15 nsps. The orfla genecodes for the ppla protein which also contains 10 nsps. According to the evolutionary tree, SARS-CoV-2 lies close to the SARS group of coronaviruses [7]

\section{Severe acute respiratory syndrome coronavirus 2 (SARS-CoV-2)}

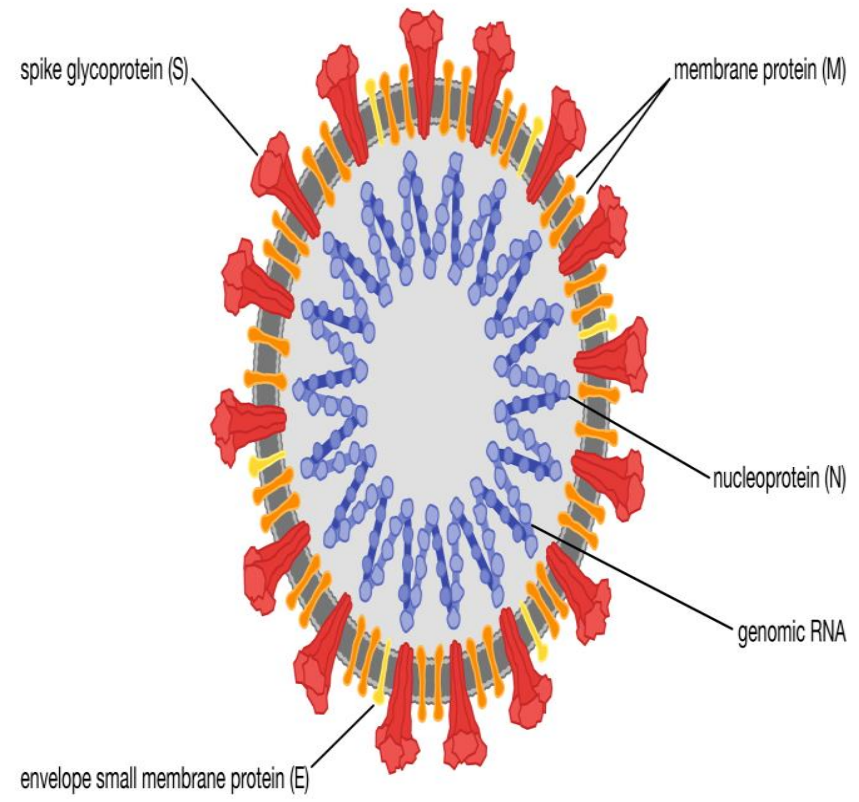

(c) Encyclopædia Britannica, Inc.

Fig.1. View of Coronavirus (SARS-COV 2)

III. Impact of Covid-19 on the mental health

The impact of the COVID-19 pandemic on mental health is complex, diverse and wide-ranging, affecting all sections of societies and populations. The tremendous increase in mental health needs is doing its damage in already aggravated mental health services, which are underfunded and with low resources in many countries on every continent affected by the COVID19 pandemic. COVID-19 has exposed serious gaps in mental health care, and now more than ever world leaders must prioritize and ensure that quality mental health support is accessible to all, everywhere.[8]

The effect that this crisis has had on the mental health of the population, both in the short and long term, is unknown. In the acute phase, fears of possible exposure to infection, loss of employment, and financial strain are likely to increase psychological distress in the wider population. This concern may be exacerbated in individuals who have experienced previous traumatic events. In the long run, grief and trauma are likely to appear as financial and social impacts become ingrained, the risk of depression and suicide may increase. The risk for psychological distress may also be greater for people employed in occupations that potentially expose them to infection and for those who have friends or family members who are infected. [9]
The COVID-19 pandemic and the resulting economic recession have negatively impacted the mental health of many people and created new barriers for people already suffering from mental illness and substance use disorders. Many adults report specific negative impacts on their mental health and well-being, such as difficulty sleeping $(36 \%)$ or eating $(32 \%)$, increased alcohol or substance use (12\%), and worsening conditions chronic (12\%), due to anxiety and stress on the coronavirus. [10]

In the US $45 \%$ of adults have reported experiencing anxiety and stress, these numbers are likely to increase as people continue to physically distance themselves as well as worry about COVID-19 disease. In the UK, about $33 \%$ of people are said to have experienced high levels of anxiety since the onset of the pandemic while in Italy a study identified symptoms of post-traumatic stress $(37 \%)$, stress $(21 \%)$, severe anxiety $(20 \%)$, symptoms of depression $(17 \%)$ and insomnia $(7 \%)$ among respondents. [11]

The current rate of COVID-19 mental health burden has only just begun to appear, the effects are likely to remain long after pandemic treatment. In many ways, the threat to people's mental health seems to be invisible and vague, something that requires urgent attention however. Describing the mental health problems associated with COVID-19 as a "slow-moving catastrophe" is very appropriate as the psychological consequences are likely to be widespread and persistent. With blockages and physical distancing strategies being imposed on most nations, people have turned to various media sources to get the latest pandemic news. Using these sources of information for extended periods of time will most likely increase anxiety and the potential for hysteria thus affecting one's mental well-being.[12]

The COVID-19 pandemic has had a major effect on our lives. Many of us are facing challenges that can be stressful, overwhelming, and cause strong emotions in adults and children. Public health actions, such as social distancing, are necessary to reduce the spread of COVID-19, but they can make us feel isolated and lonely and can increase stress and anxiety. Learning to cope with stress in a healthy way will make you, the people you care about, and those around you become more resilient.

Stress can cause the following:

- Feelings of fear, anger, sadness, worry, numbness, or frustration

- Changes in appetite, energy, desires, and interests

- Difficulty concentrating and making decisions

- Difficulty sleeping or nightmares

- Physical reactions, such as headaches, body pains, stomach problems, and skin rashes

- Worsening of chronic health problems

- Worsening of mental health conditions 
- Increased use of tobacco, alcohol, and other substances

It is natural to feel stress, anxiety, grief, and worry during the COVID-19 pandemic. [13]

Mental health experts around the world have linked the increased psychological distress to public health measures used to mitigate the spread of the virus. Enforced lockdowns, quarantines, restrictions in social and family gatherings, disruption of non-essential services delivery, and suspension of cultural and sporting activities have all been identified as new stressors and factors exacerbating mental health disorders. These restrictions combined with fear of contracting the virus, food insecurity, permanent and temporary layoff, relationship struggles, loneliness, boredom, and lifestyle changes (e.g., working from home, homeschooling) have had an enormous impact on the psychosocial and economic well-being of the general population. Chronic psychological distress increases the risk of developing physical and mental health conditions such as high blood pressure, digestive problems, autoimmune diseases, sleep disturbances, psychological disorders, and memory and concentration deficits. Moreover, psychological distress is also highly associated with various hearing problems such as age-related hearing loss, sudden idiopathic sensorineural hearing loss, tinnitus, and hyperacusis. [14]

\section{Current situation with COVID 19 in Kosovo}

The current situation with Covid-19 in Kosovo is aggravated given the number of cases of infected and dead people nationwide. The number of infected people has started to decline in recent days after protective measures were taken by the Government, NIPHK and the Ministry of Health. These measures include: restriction of movement, continuous wearing of the mask, not allowing the gathering of citizens in public places. It is also worth noting that the cities are divided into 3 areas: a) green area, b) yellow area, c) red area, limiting the movement schedule to cities which have a large number of infected per capita. From the beginning of June, in Kosovo, the gradual easing of protection measures has begun, greatly enabling the release of the movement. The release of the masses has made people come back with constructed behaviors and try to adapt to a new reality. Anxiety, fear, insecurity and lack of self-confidence are some of the main problems that people faced during quarantine and that they may face after the release of the measures. The part of society which has had various emotional problems or crises even before the pandemic will find it much more difficult to recover. Decreased self-esteem is always accompanied by decreased self-esteem. And when we reach a stage with very low selfesteem and feel like a loser it is the hardest and most painful moment in terms of spiritual pain. These moments not infrequently sadly, can even end in suicide. In addition to the negative side, quarantine has also had positive effects. This time has served to strengthen cohesion with the family and increase the dose of creativity which has been expressed through art. It is also worth noting that the Mental Health Center has made available the toll-free hotline 080088881 in advising citizens on any mental health concerns during the pandemic.[15]
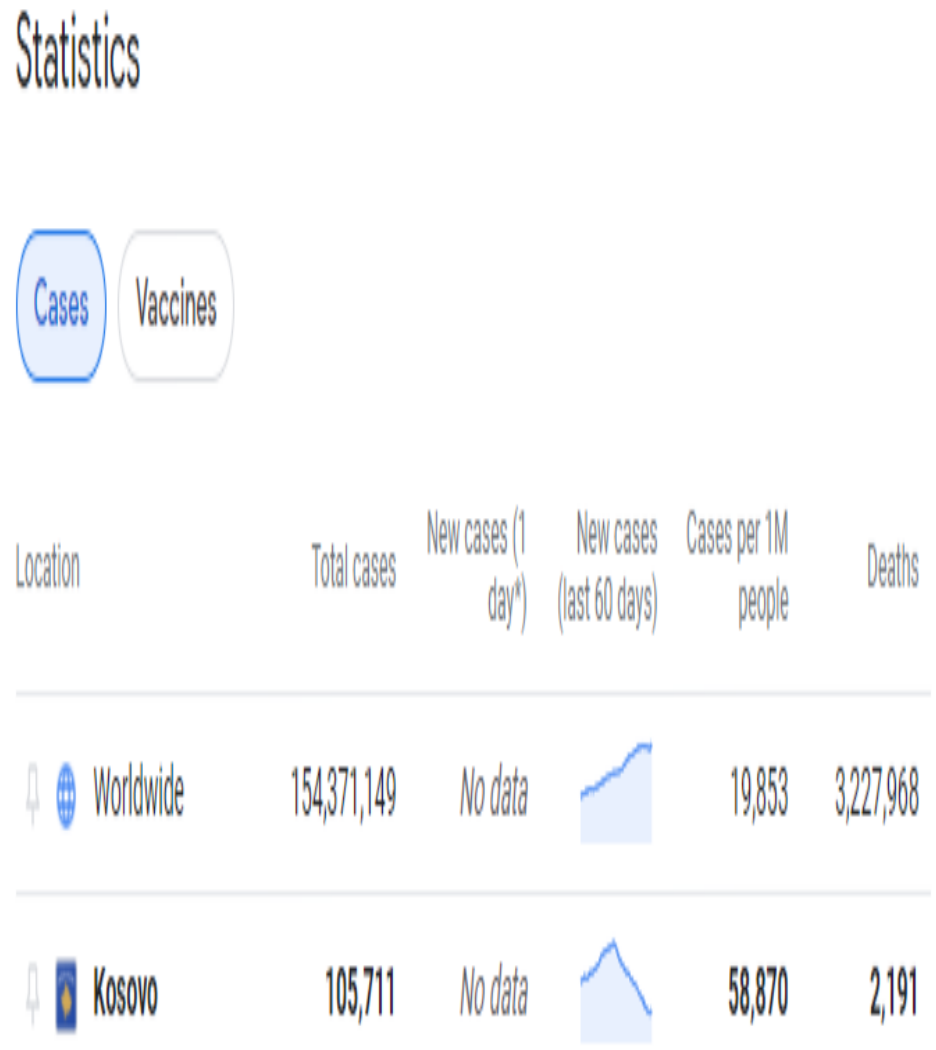

Table 1. Number of cases of infected, cases per 1 Milloin people and dead persons from Covid 19, in Kosovo and in the World

Table 1 description: currently in Kosovo there are 105,711 people infected with COVID-19. Of these, 2191 have died and the number of infected cases per 1 million inhabitants is 58,870 .

While in the world infected with the COVID-19 virus are $154,371,149$. The number of deaths worldwide is $3,227,968$. The number of cases of infected persons per 1 million inhabitants is 19,853 .

\section{Methods}

Quantitative study method was used for the realization of this work. The material used for this study was taken from scientific journals, World Health Organization (WHO), Kosovo National Institute of Public Health (NIPHK), European Center for Disease Prevention and Control (ECDC). This paper is based on the data extracted from the 
questionnaire completed together with the citizens of the municipalities of Prizren and Gjakova. For the realization of this scientific research are involved 200 citizens. Age groups, gender, economic status, level of education and place of residence were also analyzed. The study included people aged 20 to 50 years. The most included gender in the study is the female with $59 \%$ while the male gender with $41 \%$. All results are presented in graphs worked with SPSS program.

The instrument used for this scientific paper is structured by Rek, Freeman, Reinhard, Keeser, Padberg (2020). The questionnaire includes 18 questions, of which 5 include demographic data (age, gender, place of residence, level of education and economic status), while the other 13 questions are directly related to the topic we addressed.

\section{Purpose and objectives}

The purpose of this paper is to verify how much the pandemic and the situation with COVID-19 have affected the mental health of the population in the city of Prizren and Gjakova.

The objectives are:

- Introduction to COVID-19

- Identification of new cases of COVID-19 and deaths in the world and Kosovo

- Impact of COVID-19 on the mental health of the population

Hypotheses :

- Most citizens are not afraid of COVID-19.

- 2. Assistance provided by health professionals to deal with the pandemic, has improved the mental state of citizens

- 3. The vast majority of citizens have experienced anxiety and stress disorders at the time of COVID-19 onset.

\section{VII.Results}

The age groups included in the study dominated by the age group 20-30 years with $38.5 \%$ while the lowest participation in the study has the age group $31-40$ with $28.5 \%$. 59\% are female and $41 \%$ male. Based on the answers of the respondents about $90 \%$ answered that they have average economic status, $8.5 \%$ with low economic status while $1.5 \%$ stated that they have high economic status. $27 \%$ of the sample are with primary level of education and $5.5 \%$ with Master level of education. Only $40.5 \%$ of respodents live in urban area while in rural area $59.5 \%$. $85.5 \%$ of respondents report disagreeing that they tested positive for Covid-19. The remaining $13.5 \%$ fully agree. The data show that: $49 \%$ of them do not have someone close to them infected with COVID-19 while $38.5 \%$ agree that they had an infected relative. When asked if someone close to them died from COVID-19, 71.5\% disagree that someone close to them died during the pandemic and only 7\% partially agree. Respondents' answers to the question which of the factors is risk, result in $60 \%$ disagree that over 60 years of age while $37 \%$ fully agree that this factor is risky. More than half of $52 \%$ of citizens fully agree that persons with concomitant diseases are persons at high risk. $24.5 \%$ of respodents fully agree that the loss of immunity is a risk factor for COVID-19 and 1\% are neutral. Negative habits according to the respondents' report are in danger for their lives where $92 \%$ of them report that they do not agree and only $6 \%$ of them fully agree. Results reports that quarantine has affected the emotional state as in this question $36 \%$ of respondents answered in complete agreement and only $10.5 \%$ disagree. At the time of quarantine respondents stated: $26.5 \%$ fully agree that they felt as if they were choking, $17 \%$ are neutral, $36 \%$ disagree. The results show that $34 \%$ of respondents fully agree that quarantine has negatively affected their work and profession and only 3\% disagree in part. The assistance provided by health professionals has improved the situation of the respondents, therefore the results show that in this aspect 34\% fully agree and $12.5 \%$ are neutral and $21.3 \%$ do not agree. Anxiety and stress disorders were presented to respondents at the time of onset of Covid-19 disagree 33\% while fully agree $26.5 \%$, partially agree $18.5 \%$. Are well fed at the time of quarantine $79 \%$ fully agree, partially disagree $1.5 \%$ neutral are only $4.5 \%$. Counseling by health professionals at the time of the pandemic was conducted therefore results report 53.5\% fully agree, neutral 5.5\% and disagree $14 \%$. The results reports that $40 \%$ disagree that they are afraid of Covid-19, of which $17 \%$ fully agree, $16 \%$ are neutral and only $21.5 \%$ partially agree.

\section{Student T-test analysis}

T-test analysis has shown significant differences between females (mean $2.95 \pm .48$ ) and males (mean $2.34 \pm .34$ ) in terms of their fear of Covid-19 which showed that females scored higher scores, $\mathrm{t}=2.731, \mathrm{p}=.007$.

Table 1. Differences between women and men regarding fear of Covid-19

\begin{tabular}{lllllll}
\hline & $\mathrm{n}$ & Mean & $\mathrm{SD}$ & $\mathrm{t}$ & $\mathrm{df}$ & $\mathrm{p}$ \\
\hline Female & 118 & 2.95 & .48 & 2.731 & 198 & .007 \\
Male & 82 & 2.34 & .34 & & & \\
& & & & & & \\
\hline
\end{tabular}

\section{Descriptive Statistics}

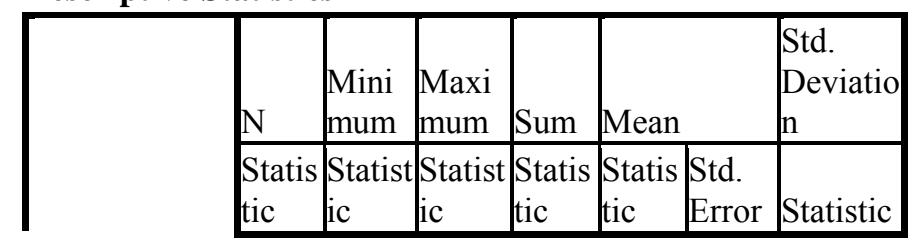




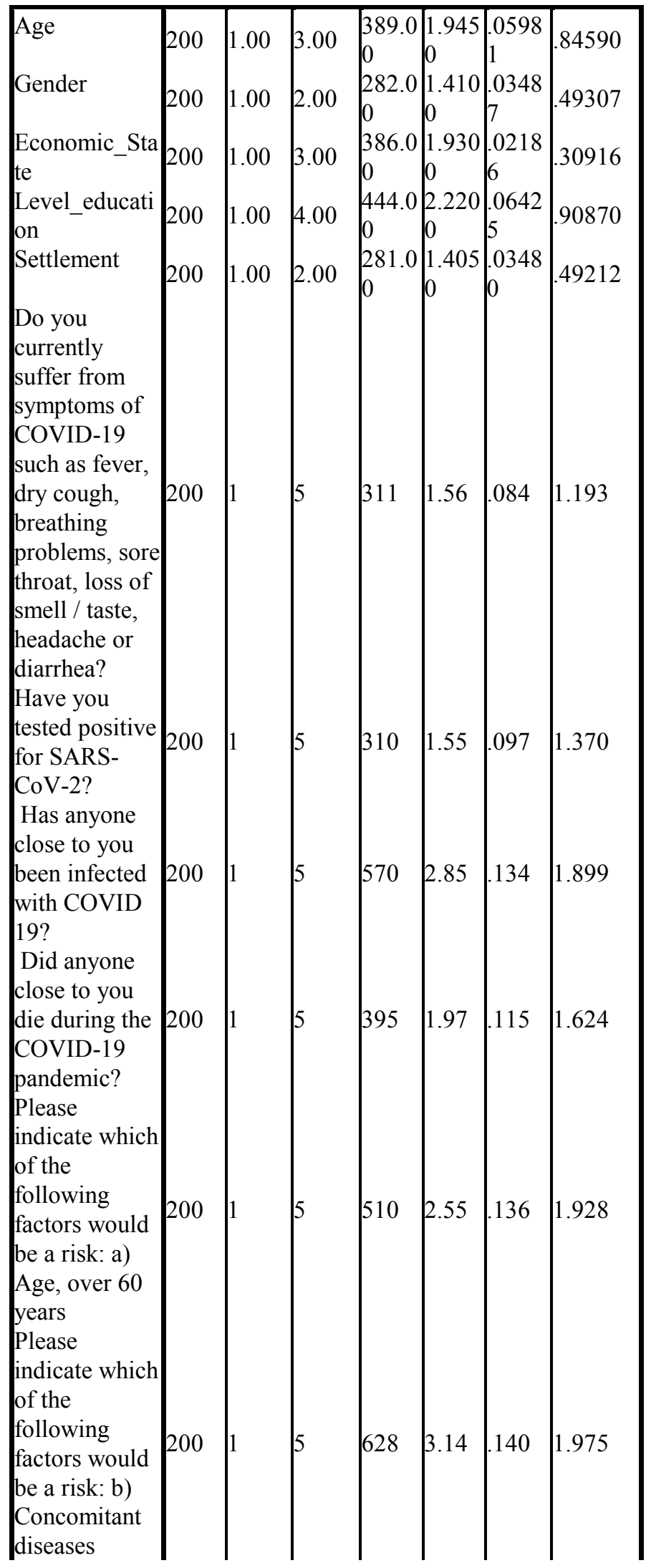

Please indicate which of the following factors would be a risk: c) Loss of immunity Please indicate which of the following factors would be a risk: d) Negative habits How much has quarantine affected your emotional state?

Do you feel like you are choking on quarantine time? Has the quarantine negatively affected your professional work?

Has the help provided by professionals to deal with the pandemic affected the improvement of your condition and that of your family members? Did you experience anxiety and stress disorders at the time of COVID-19 onset? At the time of quarantine were you well fed?

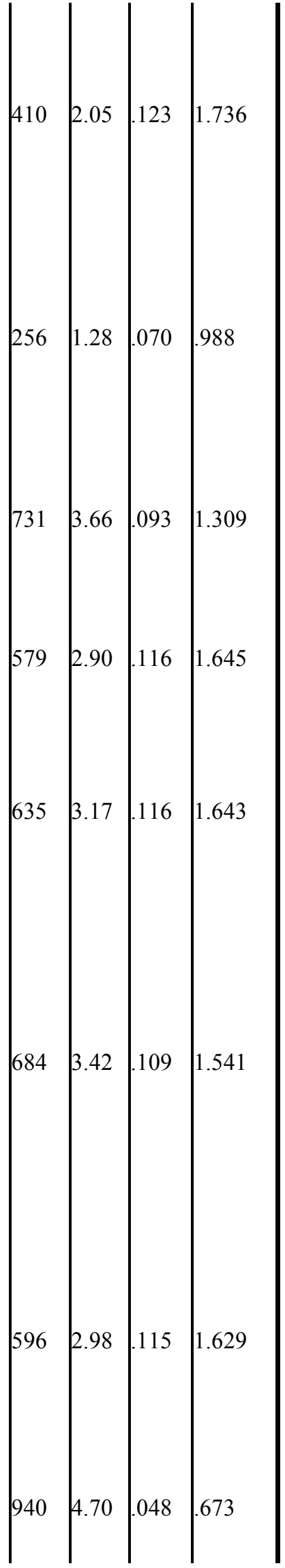




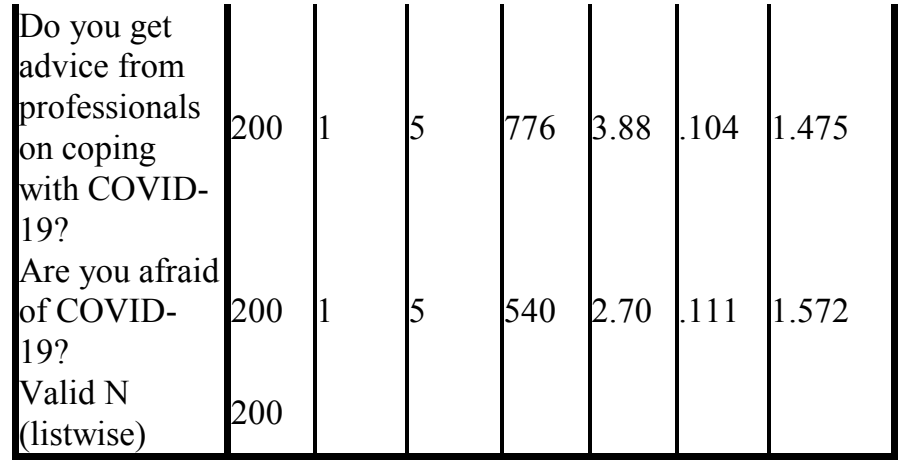

\section{DISSCUSIONS}

Generally to get COVID-19 citizens are informed up to a point about the danger that threatens they are then aware of the prevention of COVID-19, seeing that there is a lot of talk about the pandemic and in the period March 2020-January 2021 in the media then advised as well as measures taken by competent bodies such as NIPHK and the Ministry of Health. The recommendation that came from NIPHK then its approval by the Ministry of Health for quarantine is seen to have had a major impact on mental health in terms of emotional state during the time of isolation, but based on the results we have achieved, at the moment showing that COVID-19 citizens have not experienced high levels of anxiety and stress disorders. Large sections of the population around the world have experienced increased anxiety, depression, stress and loneliness as a result of the COVID-19 outbreak. No one is immune to the pressures that the pandemic has put on communities and countries. The reason for the negative impact of COVID-19 on the mental health of the population is the fact that the quarantine situation experienced by citizens has affected their professional work, which as a result has caused a decline in the economic level, even for those societies that are not affected. directly from COVID-19, the effects of isolation and economic consequences are being widelyfelt. If we compare our study with the study of the same type that was conducted in Albania, then minimal depression in Albania was experienced by $47.74 \%$ of respondents, while in Kosovo $33 \%$, mild depression in Albania expressed 31.82\% while in Kosovo $7.5 \%$ and depression moderate in Albania 12.9\% and in terms of Kosovo $18.5 \%$. From this we result that: in our country moderate depression have experienced a larger number of citizens compared to Albania.

\section{CONCLUSION}

Coronavirus infection (SARS-CoV-2) causes coronavirus disease 2019 (COVID-19). The virus that causes COVID-19 spreads easily among humans and more continues to be detected over time as to how it spreads. Signs and symptoms of coronavirus disease 2019 (COVID-19) may appear 2 to 14 days after exposure. From 31 December 2019 to 12 December 2020, 70,332,414 cases of COVID-19 were reported (consistent with applied case definitions and testing strategies in affected countries), including 1,596,000 deaths. Anxiety, fear, insecurity and lack of self-confidence are some of the major problems that people face during quarantine. Lack of hugs, handshakes, free movement and isolation have made it impossible for people to socialize and behave normally with each other. It has been proven that quarantine has affected the emotional state as $36 \%$ of respondents responded with fully agree and only $10.5 \%$ disagree. At the time of quarantine respondents stated: $26.5 \%$ fully agree that they felt they were choking, $17 \%$ are neutral, $36 \%$ disagree. It was found that $33 \%$ of respondents did not have anxiety and sleep disorders while $26.5 \%$ of them fully agree. We also highlighted the importance of good nutrition, with $79 \%$ of participants saying they are consistently well fed, while $1.5 \%$ disagree and only $4.5 \%$ are neutral. The vast majority of citizens have also expressed that they have consistently received advice on protection from Covid-19 and emotional support from health professionals. So the help provided by doctors, nurses and other health professionals has helped them to deal with this condition as easily as possible. After analyzing and evaluating the results, two of the hypotheses were confirmed, which state that most citizens are not afraid of COVID-19 and that the help provided by health professionals to deal with the pandemic, has improved the mental state of citizens. While the hypothesis which cites that the vast majority of citizens experienced anxiety and stress disorders at the time of COVID-19 onset, is not fully substantiated because a significant number have expressed that they have not experienced mental disorders. 


\section{RECOMMANDATIONS}

Considering the importance of the advice, suggestions and recommendations of health professionals for protection against COVID-19 and to promote complete mental health then it is recommended:

- In the first place, the observance of anticovid measures such as: physical distance, wearing a mask, personal hygiene, avoiding crowds, ventilation of the spaces where we stay.

- Extra care to keep the situation under control, if you belong to the group of people infected with COVID19.

- Contact your family doctor if you suspect you have been affected by COVID-19, get advice from him or her on managing your symptoms.

- In addition to constant consultation with the doctor regarding physical health, communication with a psychologist is more than necessary.

- Performing regular physical activity, as being active is not only great for physical health but also helps improve mental well-being by: raising your selfesteem by helping you set goals or challenges and achieve them by causing chemical changes in your brain which can help to positively change your mood.

- Add importance to sleep, get enough sleep.

- Find a safe and controlled way to recognize and express your difficult emotions, for example by writing them down in a diary or letter, talking to a friend or practicing yoga or meditation.

- While you are in isolation, try to contact your relatives by phone or social networks, in order to alleviate the feeling of loneliness.

- Keep physical distance and not social distance, as exchanges and occasional and friendly relationships that negatively affect mental health.

- Avoid information related to conspiracy theories which increase stress and insecurity.

- Individuals should try in a special and indirect way to create continuous connections and not to sever them.

- Ongoing emotional support from individuals affected by COVID-19 and those at risk, from health professionals, psychologists and social workers, is recommended.

\section{Appendix}

Instrument (Questionnaire)

Age: $20-30 ; 31-40 ; 41-50$

Economic situation: Low; Medium; High

Level of education: Primary; High School; Bsc; Msc

Residence: Rural; Urban 


\begin{tabular}{|c|c|c|c|c|c|c|}
\hline Nr. & & I do not agree & $\begin{array}{l}\text { I partially } \\
\text { disagree }\end{array}$ & Neutral & $\begin{array}{l}\text { I partially } \\
\text { agree }\end{array}$ & I totally agree \\
\hline 1. & $\begin{array}{l}\text { Do you currently suffer from } \\
\text { symptoms of COVID-19 to work } \\
\text { like fever, dry cough, breathing } \\
\text { problem, sore throat, loss of smell / } \\
\text { taste, headache or diarrhea? }\end{array}$ & & & & & \\
\hline 2. & $\begin{array}{l}\text { Have you tested positive for SARS- } \\
\text { CoV-2? }\end{array}$ & & & & & \\
\hline 3. & $\begin{array}{l}\text { Has anyone close to you been } \\
\text { infected with COVID } 19 ?\end{array}$ & & & & & \\
\hline 4. & $\begin{array}{l}\text { Did anyone close to you die during } \\
\text { the COVID-19 pandemic? }\end{array}$ & & & & & \\
\hline 5. & $\begin{array}{l}\text { Please indicate which of the } \\
\text { following factors would be a risk: } \\
\text { a) Age, over } 60 \text { years } \\
\text { b) Concomitant diseases } \\
\text { c) Loss of immunity } \\
\text { d) Negativ habits }\end{array}$ & & & & & \\
\hline 6. & $\begin{array}{l}\text { How much has quarantine affected } \\
\text { your emotional state? }\end{array}$ & & & & & \\
\hline 7. & $\begin{array}{l}\text { Do you feel like you are drowning in } \\
\text { quarantine time? }\end{array}$ & & & & & \\
\hline 8. & $\begin{array}{l}\text { Has the quarantine negatively } \\
\text { affected your professional work? }\end{array}$ & & & & & \\
\hline 9. & $\begin{array}{l}\text { Has the help provided by } \\
\text { professionals to deal with the } \\
\text { pandemic affected the improvement } \\
\text { of your condition and that of your } \\
\text { family members? }\end{array}$ & & & & & \\
\hline 10. & $\begin{array}{l}\text { Did you experience anxiety and } \\
\text { stress disorders at the time of } \\
\text { COVID-19 onset? }\end{array}$ & & & & & \\
\hline 11. & $\begin{array}{l}\text { At the time of quarantine were you } \\
\text { well fed? }\end{array}$ & & & & & \\
\hline 12. & $\begin{array}{l}\text { Do you get advice from } \\
\text { professionals on dealing with } \\
\text { COVID-19? }\end{array}$ & & & & & \\
\hline 13. & Are you afraid of COVID-19? & & & & & \\
\hline
\end{tabular}




\section{ACKNOWLEDGMENT}

The authors thank the University of Gjakova "Fehmi Agani" for the continuous support, also thank the participants in the research.

\section{REFERENCES}

[1] Raka, L. (2020, April 16).

[2] World Health Organisation, COVID 19, https://covid19.who.int/. (2020).

[3] Mayo, C. (2020). Coronavirus Disease. Mayo Clinic Journal.

[4] Kowsar Sheikhi, Hamidreza Shirzadfar, Milad Sheikhi (2020). A Review on Novel Coronavirus (Covid-19): Symptoms, Transmission and Diagnosis Tests. ResearchGate, 1-8.

[5] Lauren M.Sauer, Hopkins Medicine 2020

[6] Galo Guillermo Farfán Cano, A Perspective about Coronavirus Disease 2019 (COVID-19), Digital Scientific Journal, 2020

[7] Muhammad Adnan Shereena, Suliman Khana, Abeer Kazmic, Nadia Bashira, Rabeea Siddique, Journal of Advanced Research, 2020, 91-98

[8] Daniels Ingrid, World Federation for Mental Health, Impact of Covid-19 on Mental Health, May 2020

[9] Dawel A, Shou Y, Smithson M, Cherbuin N, Banfield M, Alison L, Farrer L, Gray D, Gulliver A, Housen T, McCallum S, Morse A, Murray K, Newman E, Rodne E, FRONTIERSIN JOURNAL, The effect of coronavirus disease on mental health, 2020

[10] Nirmita Panchal, Rabah Kamal, Kendal Orgera, Cynthia Cox, RachelL Garfield, Liz Hamel, Cailey Muñana, Priya Chidambaram, KFF, 21 August 2020

[11] Semo B, Frissa SM, Dovepress Journal, 3 September 2020 Volume 2020: 13 Pages 713-720

[12] Akaninyene Otu1, Carlo Handy Charles, Sanni Yaya, International Journal of Mental Health Systems, Mental health and psychosocial well-being during the COVID-19 pandemic: the invisible elephant in the room, 2020
[13] https://www.cdc.gov/coronavirus/2019-ncov/dailylife-coping/managing-stress-anxiety.html

[14] Pineault, Dany AuD, https://journals.lww.com/thehearingjournal/fulltext/2021 /03000/impact_of_covid_19_pandemic_on_mental_heal th_and.10.aspx

[15] Rexhepi S, Kallxo.com, 08 June 2020

\section{Authors:}

Donart Koci- last year student at the Faculty of Medicine, Department of Nursing, at the University of Gjakova "Fehmi Agani". Works as a tutor of clinical practice at the Faculty of Medicine. Has published a scientific paper (Palliative Care for the Elderly) in JOSHA Journal. He participated in the palliative care course in Ghent, Belgium and in training in Manisa, Turkey. Participated in many international conferences, congresses and workshops related to the field of medicine.

Festina Morina- graduated from the high school of medicine "Luciano Motroni" - Prizren, is currently a student in the last year of studies at the Faculty of Medicine, Department of Nursing, at the University of Gjakova "Fehmi Agani". She has participated in several conferences and trainings related to the field of medicine. Works as a tutor for the module "Internal Diseases" at the Faculty of Medicine.

Fatlinda Hoxhaj, last year student at the Faculty of Medicine, Department of Nursing, at the University of Gjakova "Fehmi Agani". Works as a tutors in the field of nursing of at the Faculty of Medicine. Participated in many international conferences, congresses and workshops related to the field of medicine.

*Antigona Ukëhaxhaj - Professor at the University of Gjakova "Fehmi Agani", Vice Dean at the Faculty of Medicine. Mentor and corrospondent author .

\section{Author Contributions:}

-Donart Koci has researched the literature and critically evaluated it by selecting relevant materials related to the topic. -Festina Morina interviewed the research participants by completing the questionnaires and systematized them in the SPSS program by extracting the data together with various operations- Fatlinda Hoxhaj commented on the results and drew some conclusions.

All the authors together have come to conclusions and validated the hypotheses and then we came up with some recommendations regarding how to care for mental health during the time of the pandemic. 


\section{Creative Commons Attribution License 4.0} (Attribution 4.0 International, CC BY 4.0)

This article is published under the terms of the Creative Commons Attribution License 4.0

https://creativecommons.org/licenses/by/4.0/deed.en US 